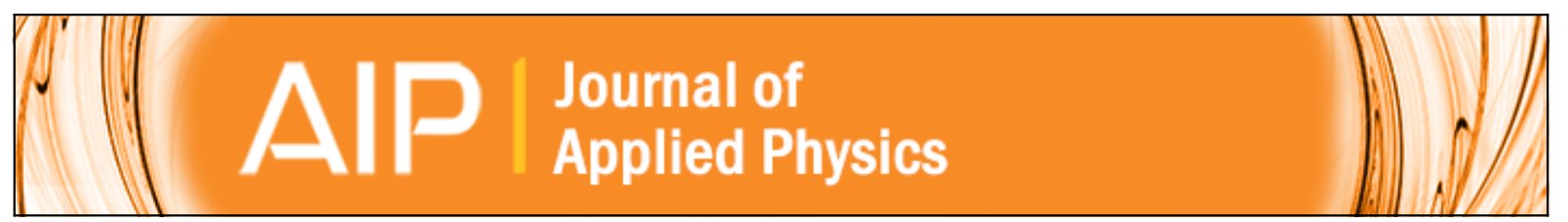

\title{
Hydrogen passivation of interstitial iron in boron-doped multicrystalline silicon during annealing
}

AnYao Liu, Chang Sun, and Daniel Macdonald

Citation: Journal of Applied Physics 116, 194902 (2014); doi: 10.1063/1.4901831

View online: http://dx.doi.org/10.1063/1.4901831

View Table of Contents: http://scitation.aip.org/content/aip/journal/jap/116/19?ver=pdfcov

Published by the AIP Publishing

\section{Articles you may be interested in}

Precipitation of iron in multicrystalline silicon during annealing

J. Appl. Phys. 115, 114901 (2014); 10.1063/1.4868587

Influence of hydrogen on interstitial iron concentration in multicrystalline silicon during annealing steps

J. Appl. Phys. 113, 114903 (2013); 10.1063/1.4794852

Diffusion of co-implanted carbon and boron in silicon and its effect on excess self-interstitials

J. Appl. Phys. 111, 073517 (2012); 10.1063/1.3702440

Understanding the distribution of iron in multicrystalline silicon after emitter formation: Theoretical model and experiments

J. Appl. Phys. 109, 063717 (2011); 10.1063/1.3553858

Effects of boron-interstitial silicon clusters on interstitial supersaturation during postimplantation annealing Appl. Phys. Lett. 79, 1103 (2001); 10.1063/1.1396310

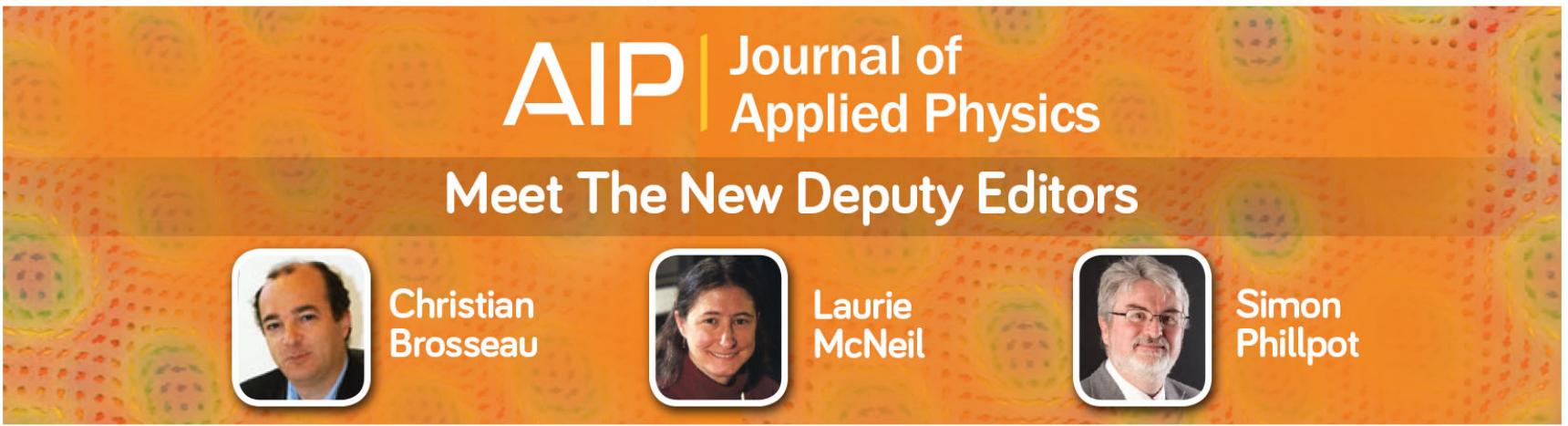




\title{
Hydrogen passivation of interstitial iron in boron-doped multicrystalline silicon during annealing
}

\author{
AnYao Liu, Chang Sun, and Daniel Macdonald \\ Research School of Engineering, the Australian National University, Canberra, ACT 0200, Australia
}

(Received 11 August 2014; accepted 4 November 2014; published online 21 November 2014)

\begin{abstract}
Effective hydrogenation of interstitial iron in boron-doped multicrystalline silicon wafers is reported. The multicrystalline silicon wafers were annealed with plasma-enhanced chemical vapour deposited silicon nitride films, at temperatures of $400{ }^{\circ} \mathrm{C}-900^{\circ} \mathrm{C}$ and for times from minutes to hours. At low temperatures where a combined effect of hydrogenation and precipitation of dissolved $\mathrm{Fe}$ is expected, results show that the hydrogenation process dominates the effect of precipitation. The concentrations of dissolved interstitial iron reduce by more than $90 \%$ after a 30-min anneal at temperatures between 600 and $900{ }^{\circ} \mathrm{C}$. The most effective reduction occurs at $700^{\circ} \mathrm{C}$, where $99 \%$ of the initial dissolved iron is hydrogenated after $30 \mathrm{~min}$. The results show that the observed reductions in interstitial Fe concentrations are not caused by the internal gettering of $\mathrm{Fe}$ at structural defects or by an enhanced diffusivity of $\mathrm{Fe}$ due to the presence of hydrogen. The hydrogenation process is conjectured to be the pairing of positively charged iron with negatively charged hydrogen, forming less recombination active Fe-H complexes in silicon. (C) 2014 AIP Publishing LLC.

[http://dx.doi.org/10.1063/1.4901831]
\end{abstract}

\section{INTRODUCTION}

Iron $(\mathrm{Fe})$ is a common contaminant in silicon, especially prevalent in multicrystalline silicon (mc-Si) materials. ${ }^{1-3}$ Iron significantly degrades the silicon material quality by acting as deep-level recombination centres, leading to reduced minority carrier lifetime and solar cell efficiency. ${ }^{1,4}$ Mitigating the detrimental effect of $\mathrm{Fe}$ in silicon is therefore of great interest. External gettering of Fe during a phosphorous diffusion step at high temperatures is the most common and effective method used in the photovoltaic industry. ${ }^{5}$ The efficacy of this external gettering process can be further improved by a follow-up anneal at lower temperatures for extended hours, taking advantage of the increased segregation ratio between the gettering layer and the wafer bulk..$^{6-8}$ The process of external gettering moves the dissolved $\mathrm{Fe}$ atoms from the silicon bulk to the diffused regions on the wafer surfaces, achieving a reduction of the dissolved $\mathrm{Fe}$ concentration in the bulk by 1-2 orders of magnitude or more. ${ }^{5,9}$ Internal gettering of Fe by the structural defects in mc-Si has also been shown to cause a reduction of the dissolved Fe concentration by 1-2 orders of magnitude. ${ }^{10}$ This process, however, is generally slower, as it requires low to moderate temperatures to reduce the Fe solubility limit enough to drive precipitation, and the Fe diffusivity at such temperatures becomes one of the limiting factors. ${ }^{10}$ To achieve very thorough removal of the dissolved iron atoms, both external and internal gettering processes require long hours.

The benefit of hydrogen for silicon materials has been widely recognised. Hydrogen is known to passivate a wide range of defects and impurities in silicon, including vacancies, extended defects, shallow dopants, non-metallic and metallic impurities. ${ }^{11,12}$ Several authors reported a reduction of the electrical activity and concentration of iron point defects after the incorporation of atomic hydrogen into the silicon bulk. ${ }^{13-18}$ Studies using deep-level transient spectroscopy (DLTS) shows that the peaks of iron-related energy levels disappear or reduce after either hydrogen plasma exposure ${ }^{14}$ or hydrogen ion implantation. ${ }^{13}$ The concentrations of dissolved interstitial iron are found to decrease after hydrogen incorporation, either via firing of hydrogen-containing silicon nitride films ${ }^{15-17}$ or exposure to a hydrogen plasma. ${ }^{18}$ The exact mechanism for this phenomenon, however, remains unclear. While some attribute it to the hydrogen passivation of iron, ${ }^{13-17}$ others believe it to be the gettering of metals by hydrogen-enhanced metal diffusivity. ${ }^{18,19}$ In either case, the presence of hydrogen provides an additional method for reducing the harmful impact of dissolved $\mathrm{Fe}$ in silicon. In addition, the process has the potential to be more time efficient than the external or internal gettering processes, due to the high diffusivity of hydrogen in silicon. ${ }^{20}$

In this paper, we aim to study the mechanism for the reduced interstitial iron concentration after hydrogen incorporation into multicrystalline silicon. Atomic hydrogen is introduced into the mc-Si bulk via annealing the wafers with plasma-enhanced chemical vapour deposited (PECVD) silicon nitride $\left(\mathrm{SiN}_{\mathrm{x}}\right)$ films, which is a common solar cell fabrication step for the firing of metal contacts. In this study, annealing was carried out for a range of temperatures from $400^{\circ} \mathrm{C}$ to $900^{\circ} \mathrm{C}$ and for times from $3 \mathrm{~min}$ to $5 \mathrm{~h}$. To distinguish the effect of hydrogen from coincident temperaturedriven effects, such as precipitation at structural defects, sister mc-Si wafers are subject to the same annealing steps in the absence of atomic hydrogen. A recent study by Hallam et $a l .{ }^{21}$ has shown that the possible hydrogenation of boronoxygen defects depends on the presence of light-generated excess carriers, which is thought to change the charge states of hydrogen. In this paper, we also study the effect of illumination on the hydrogenation of iron through simulation and experiments. The minority carrier lifetime and the 
concentration of interstitial Fe atoms are measured by the calibrated photoluminescence (PL) imaging technique. ${ }^{22-24}$ This also enables the examination of the changes in the spatial distributions on high resolution lifetime and Fe images before and after different anneals, providing further insights into the hydrogenation mechanism.

\section{EXPERIMENT}

The multicrystalline silicon wafers were sourced from a commercially grown boron-doped directionally solidified ingot. Sister wafers located at $29 \%$ from the bottom of the ingot were chosen for this study, with a resistivity of around $1.4 \Omega \mathrm{cm}$. The $12.5 \times 12.5 \mathrm{~cm}^{2}$ wafers were diced into smaller pieces of $4.15 \times 4.15 \mathrm{~cm}^{2}$ in size for ease of processing. The mc-Si wafers have an average grain size of $17 \mathrm{~mm}^{2}$ with a standard deviation of $50 \mathrm{~mm}^{2}$, as a result of a large variation in grain sizes. The samples were then chemically polished, resulting in final thicknesses in the range of 280-300 $\mu \mathrm{m}$. Float-zone (FZ) boron-doped silicon wafers of $1.7 \Omega \mathrm{cm}$ and $240 \mu \mathrm{m}$ thickness were also included and were subjected to the same processing steps, in order to monitor surface passivation and possible process contamination.

Some of the wafers were cleaned and passivated by silicon nitride $\left(\mathrm{SiN}_{\mathrm{x}}\right)$ films using PECVD. Although the set temperature for the $\mathrm{PECVD}$ reactor is $450{ }^{\circ} \mathrm{C}$, the actual temperature on the samples during the deposition process, as measured by an infrared sensor, is about $250{ }^{\circ} \mathrm{C}$. The deposited $\mathrm{SiN}_{\mathrm{x}}$ films are $80 \mathrm{~nm}$ thick. Some of the samples were then annealed at $400{ }^{\circ} \mathrm{C}$ in a quartz tube furnace in a nitrogen ambient for various cumulative times. Some degradation of the $\mathrm{SiN}_{\mathrm{x}}$ films was observed after the $400^{\circ} \mathrm{C}$ anneals on the FZ samples. However, the minority carrier lifetime due to surface recombination remained much higher than the lifetime of the mc-Si wafers, which are limited by the bulk defects. Hence, surface degradation does not affect the measured effective lifetime and interstitial $\mathrm{Fe}$ concentrations. Re-coating of the $\mathrm{SiN}_{\mathrm{x}}$ films was therefore not required for the samples annealed at $400{ }^{\circ} \mathrm{C}$. Some of the other $\mathrm{SiN}_{\mathrm{x}}$ coated samples were annealed in a rapid thermal processor (RTP), whose heating functionality comes from pulsing infrared lamps. This represents the case of annealing under illumination.

Further samples were prepared for studies at higher annealing temperatures of $600-900{ }^{\circ} \mathrm{C}$. To distinguish the influence of hydrogen from temperature-induced effects, two sets of wafers underwent the same thermal annealing stepsone with the hydrogen source present via $\mathrm{SiN}_{\mathrm{x}}$ films, and the other without hydrogen, with thermally grown silicon oxide $\left(\mathrm{SiO}_{2}\right)$ layers providing surface passivation. The two sets are pairs of sister wafers. To ensure the same thermal history, both sets of the wafers were cleaned and annealed in dry oxygen at $1000^{\circ} \mathrm{C}$ for $1 \mathrm{~h}$, followed by an anneal in nitrogen for $30 \mathrm{~min}$, before being cooled down to $750^{\circ} \mathrm{C}$ at $10^{\circ} \mathrm{C} / \mathrm{min}$ and then left in a high air flow to cool to room temperature within minutes. This results in the growth of $\mathrm{SiO}_{2}$ layers as surface passivation. The high temperature process also homogenises the distributions of interstitial Fe across the mc-Si wafers. One set of the wafers were then dipped in dilute $\mathrm{HF}$ solution to remove the $\mathrm{SiO}_{2}$ layers and were re- passivated using PECVD $\mathrm{SiN}_{\mathrm{x}}$ films. Each pair of the $\mathrm{SiO}_{2}$ and $\mathrm{SiN}_{\mathrm{x}}$ passivated samples was annealed for the same temperature and time. Short anneals of minutes were performed in an RTP (at these higher temperatures, the presence or not of illumination during annealing is not expected to have any impact, as described below), while long anneals were conducted in a quartz tube furnace. The $\mathrm{SiN}_{\mathrm{x}}$ passivated samples were annealed in nitrogen, while the $\mathrm{SiO}_{2}$ samples were annealed in forming gas in order to maintain the surface passivation effect. The forming gas used in this study consists of 95\% argon and 5\% hydrogen molecules. The presence of hydrogen, however, has little bulk hydrogenation effect, as the hydrogen is trapped by the defective $\mathrm{Si}_{-} \mathrm{SiO}_{2}$ layers, which act as diffusion barriers for $\mathrm{H}_{2}$ into the bulk. ${ }^{25-27}$ This is confirmed by the results shown in this study, where little change in carrier lifetime and recombination activity of defects is found after annealing $\mathrm{SiO}_{2}$ passivated mc-Si samples in the forming gas. The $\mathrm{SiN}_{\mathrm{x}}$ coated samples experienced severe surface degradation after annealing at temperatures of $600-900{ }^{\circ} \mathrm{C}$. Therefore, after each annealing step, the degraded $\mathrm{SiN}_{\mathrm{x}}$ films were stripped off in dilute $\mathrm{HF}$ solution, and the samples were cleaned and re-passivated with fresh $\mathrm{SiN}_{\mathrm{x}}$ films, in order to measure the bulk lifetime and $\mathrm{Fe}$ concentrations.

The minority carrier lifetime, interstitial Fe concentration $\left(\left[\mathrm{Fe}_{i}\right]\right)$ and resistivity were measured after each processing step. Resistivity was determined from dark conductance data measured using a quasi-steady-state photoconductance (QSSPC) tester $^{28}$ from Sinton Instruments. Spatial distributions of lifetimes and $\mathrm{Fe}_{i}$ concentrations were obtained by using a PL imaging system ${ }^{22}$ from BT imaging. The carrier lifetimes from PL images were calculated by calibrating via an in-built QSSPC tester, using the method described in Ref. 23 to account for the inhomogeneity in mc-Si wafers. Calculation of the $\mathrm{Fe}_{i}$ concentration is based on the wellestablished method of monitoring the changes in minority carrier lifetimes before and after the dissociation of the Fe-B pairs via strong illumination. ${ }^{24,29,30}$ The pixel size of the PL images is about $23 \mu \mathrm{m}$, although the actual resolution is largely limited by the carrier diffusion length. Most of the samples have low carrier lifetimes of a few microseconds, and thus the effect of carrier diffusion smearing on the resulting $\left[\mathrm{Fe}_{i}\right]$ images is small. ${ }^{31} \mathrm{~A}$ point spread function was applied to de-convolute image smearing caused by the lateral photon scattering within the Si-CCD camera. ${ }^{32}$

\section{RESULTS}

\section{A. Hydrogen passivation of iron}

\section{Hydrogenation of iron during PECVD deposition}

Fig. 1 shows a comparison of the average interstitial Fe concentrations of the same wafers in two states - after oxidation at $1000^{\circ} \mathrm{C}$, and after stripping off the $\mathrm{SiO}_{2}$ layers followed by surface passivation using PECVD $\mathrm{SiN}_{\mathrm{x}}$. All of the tested wafers show reductions in the $\mathrm{Fe}_{i}$ concentrations, ranging from $10 \%$ to $30 \%$ after the PECVD surface passivation. The two different passivation methods result in different surface recombination lifetimes. However, the surface 


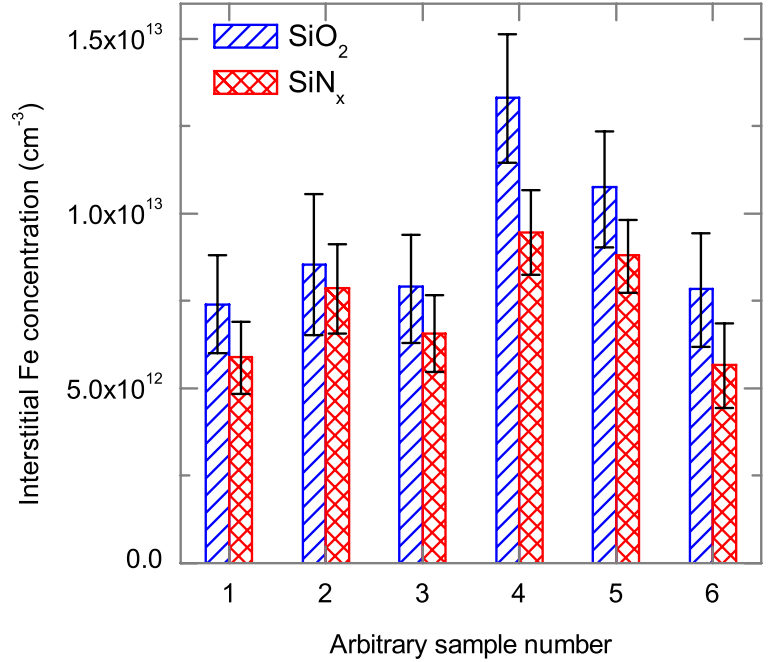

FIG. 1. Average interstitial Fe concentrations of the same wafers before (blue) and after (red) the PECVD $\mathrm{SiN}_{\mathrm{x}}$ deposition.

recombination lifetime of either of the methods is still orders of magnitude higher than the lifetime due to bulk defects, resulting in similar measured effective carrier lifetimes of the mc-Si samples. In any case, the effect of surface passivation is cancelled out in the $\left[\mathrm{Fe}_{i}\right]$ calculation. The differences in the $\mathrm{Fe}_{i}$ concentrations before and after PECVD are therefore not caused by the different passivation films, but reflect a real physical phenomenon. This was also observed previously $^{5}$ for FZ-Si wafers of known implanted Fe concentrations, which show slight reductions of $\left[\mathrm{Fe}_{i}\right]$ after repetitive PECVD $\mathrm{SiN}_{\mathrm{x}}$ depositions. Herzog et al. ${ }^{33}$ reported improved bulk lifetime after the PECVD $\mathrm{SiN}_{\mathrm{x}}$ depositions. The reduced interstitial Fe concentrations after PECVD as shown in Fig. 1 are therefore likely due to the hydrogenation of interstitial Fe during the PECVD processes.

The temperature of the samples during the PECVD depositions was monitored by an infrared sensor. In this experiment, the maximum temperature on the wafers during PECVD is about $250{ }^{\circ} \mathrm{C}$, and the samples were kept at this temperature for only a few minutes for the deposition process, after which the samples were cooled down to $150^{\circ} \mathrm{C}$ in half an hour before being removed from the reactor chamber. In comparison with the results of the $400{ }^{\circ} \mathrm{C}$ anneals in the latter part of this paper, and also those in literature, ${ }^{18,34}$ this reduction in $\left[\mathrm{Fe}_{i}\right]$ seems large for this deposition temperature and time. However, the deposition process consists of various complex reactions, including the presence of a plasma containing hydrogen and hence is not directly comparable to the process of annealing $\mathrm{SiN}_{\mathrm{x}}$ films.

\section{Effect of illumination}

The fractions of the different charge states of interstitial iron $\left(\mathrm{Fe}^{+}\right.$and $\left.\mathrm{Fe}^{\mathrm{o}}\right)$ and hydrogen $\left(\mathrm{H}^{+}, \mathrm{H}^{-}\right.$, and $\left.\mathrm{H}^{\circ}\right)$ under steady state can be estimated from their energy levels and capture cross sections, by using Shockley-Read-Hall (SRH) statistics. $^{35,36}$ Details of the model as applied to the case of hydrogen passivation in silicon can be found in Ref. 37 and in the upcoming publication by Sun et al. ${ }^{38}$
The hydrogenation of Fe may be due to the reaction of positively charged $\mathrm{Fe}$ and negatively charged $\mathrm{H}$, forming stable and less recombination active $\mathrm{Fe}-\mathrm{H}$ complexes. Other processes are also possible, such as the interaction between neutrally charged $\mathrm{Fe}$ and $\mathrm{H}$. In this study, we consider the conjecture of positive $\mathrm{Fe}$ and negative $\mathrm{H}$. The percentage of $\mathrm{Fe}^{+}$out of the total isolated interstitial $\mathrm{Fe}$, and the percentage of $\mathrm{H}^{-}$out of the total monatomic $\mathrm{H}$, are simulated and shown in Fig. 2, as a function of temperature and excess carrier injection. The calculation considers the effect of band gap narrowing with temperature, ${ }^{39}$ and assumes constant capture cross sections and constant distances between defect energy levels and the valence band, due to a lack of temperature-dependent data in the literature. As shown in Fig. 2, for a moderate injection level below $10^{16} \mathrm{~cm}^{-3}$, the effect of illumination on the percentages of charged species becomes negligible for temperatures higher than $400^{\circ} \mathrm{C}$, as the intrinsic carrier concentration becomes much higher than the excess carrier concentration. Hence, this is also true for the percentages of $\mathrm{H}^{\mathrm{o}}$ and $\mathrm{H}^{+}$.

Fig. 2 also shows that at temperatures above $400{ }^{\circ} \mathrm{C}$, the fractions of both species increase with temperature. Note that the exact magnitude of the simulated fractions becomes increasingly inaccurate at higher temperatures, due to limited
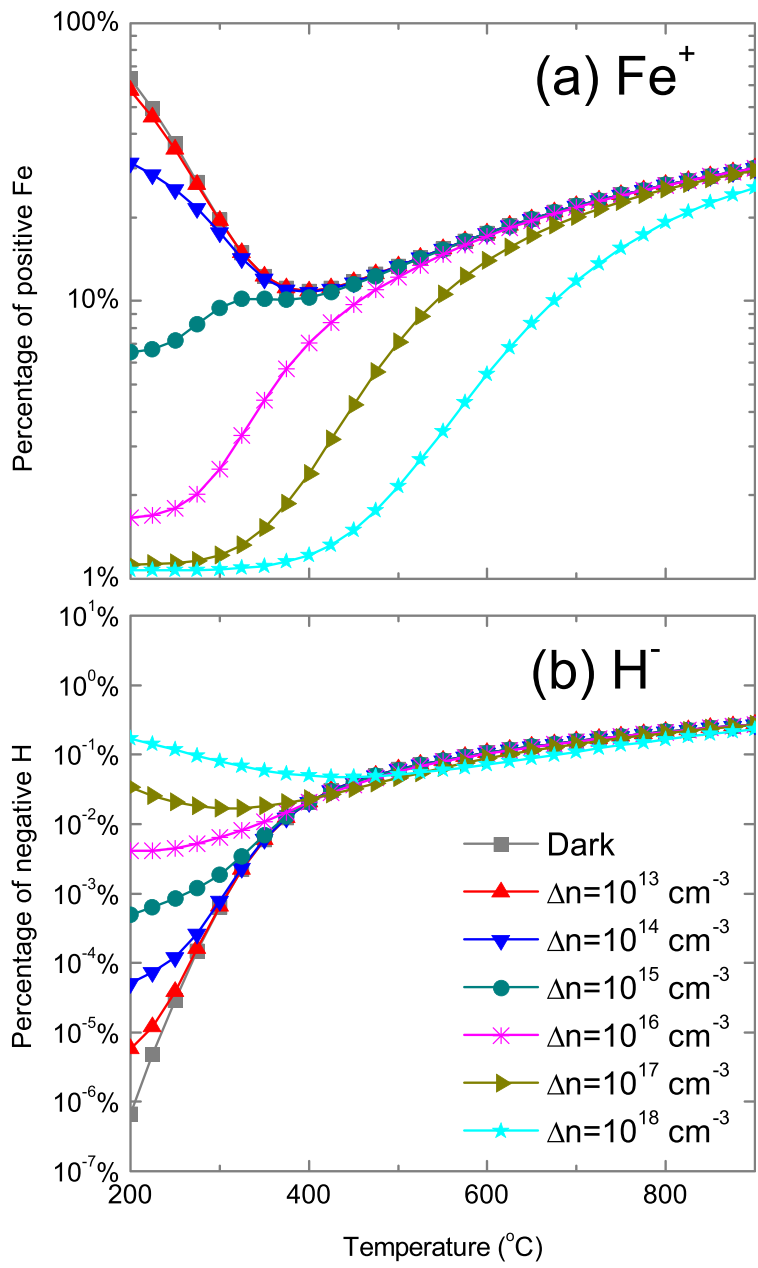

FIG. 2. Estimation of the percentage of the total isolated interstitial Fe concentration present in the positive charge state $\left(\mathrm{Fe}^{+}\right)$(top); percentage of hydrogen present in the negative charge state $\left(\mathrm{H}^{-}\right)$(bottom). 
data in the literature on the temperature-dependent parameters. However, the increasing trends of the fractions are as expected from the increasingly symmetrical carrier distributions across the band gap as the temperature increases. As the fractions of $\mathrm{Fe}^{+}$and $\mathrm{H}^{-}$increase with temperature, i.e., increasing concentrations of both reactants are available, and given that the reaction rate constant also increases with temperature as described by Arrhenius' equation, the reaction rate of $\mathrm{Fe}^{+}$and $\mathrm{H}^{-}$pairing should also increase from 400 to $900{ }^{\circ} \mathrm{C}$. It should be noted however that the reverse reaction (dehydrogenation) will, for the same reason, proceed with an increasing rate as the temperature increases, and at some point may come to dominate the forward reaction, leading to a net dehydrogenation effect.

To test the possible impact of illumination on the experiments presented here, $\mathrm{SiN}_{\mathrm{x}}$ coated wafers were annealed at $400{ }^{\circ} \mathrm{C}$ for cumulative time durations, one in an RTP which provides illumination during annealing, and one in a dark quartz tube furnace. Degradation of the $\mathrm{SiN}_{\mathrm{x}}$ films is more severe under strong flashing of the RTP, which was also observed in Ref. 17. The carrier lifetime due to surface recombination, as measured on the high quality FZ-Si samples, dropped from $1.7 \mathrm{~ms}$ to $80 \mu$ s after $50 \mathrm{~min}$ cumulative annealing in the RTP; while the surface lifetime for furnace annealed samples dropped to $110 \mu$ s after $5.5 \mathrm{~h}$. Note that the surface lifetime is still at least one order of magnitude higher than the effective lifetime of the mc-Si samples, and thus the sensitivity of the $\left[\mathrm{Fe}_{i}\right]$ measurement was maintained. As a result of the different degradation rate, the RTP annealed sample could not reach a cumulative annealing time as long as the furnace annealed sample. As shown in Fig. 3, both of the mc-Si wafers experienced reductions in the interstitial $\mathrm{Fe}$ concentrations after annealing, and the concentrations follow an exponential decay curve. The exponential reduction time constants of the two wafers are found to be similar- $170 \mathrm{~min}$ for the illuminated sample and $200 \mathrm{~min}$ for the sample annealed in the dark. The main mechanism that drives the reductions in $\mathrm{Fe}_{i}$ concentrations during the $400{ }^{\circ} \mathrm{C}$ anneals is

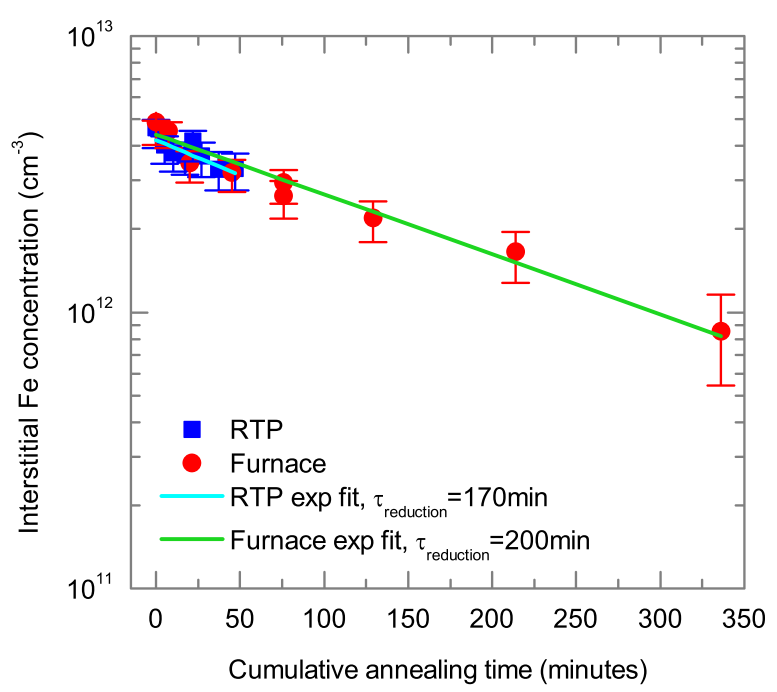

FIG. 3. Interstitial Fe concentration with respect to the cumulative annealing time for two wafers annealed at $400{ }^{\circ} \mathrm{C}$ with $\mathrm{SiN}_{\mathrm{x}}$ films, one annealed under illumination (RTP), and one in the dark (quartz tube furnace). therefore not affected by this illumination, confirming the charge state simulations shown above. Unfortunately, precise illumination intensities during RTP are not known, but it is likely that the carrier injection levels remain below $10^{16} \mathrm{~cm}^{-3}$.

The presence of atomic hydrogen is identified as the crucial element for the observed $\left[\mathrm{Fe}_{i}\right]$ reductions. In our previous work, ${ }^{10} \mathrm{mc}-\mathrm{Si}$ wafers from the same part of this ingot were also annealed at $400{ }^{\circ} \mathrm{C}$ in dark, one with $\mathrm{SiO}_{2}$ (i.e., no hydrogen source) and one with $\mathrm{Al}_{2} \mathrm{O}_{3}$ (i.e., with hydrogen source) passivation layers. The $\mathrm{SiO}_{2}$ passivated wafer resulted in a $\left[\mathrm{Fe}_{i}\right]$ reduction time constant of $1200 \mathrm{~min}$, while the one with $\mathrm{Al}_{2} \mathrm{O}_{3}$ films gave a time constant of $210 \mathrm{~min}$. In Ref. 34, a $\mathrm{SiN}_{\mathrm{x}}$ coated mc-Si wafer annealed at $400{ }^{\circ} \mathrm{C}$ shows a $\left[\mathrm{Fe}_{i}\right]$ reduction time constant of $100 \mathrm{~min}$. In Ref. 18, atomic hydrogen was introduced into the silicon bulk by subjecting mc-Si wafers to a hydrogen plasma at $400{ }^{\circ} \mathrm{C}$. From the changes in $\left[\mathrm{Fe}_{i}\right]$ after the hydrogen plasma step, the average reduction time constant is estimated to be $280 \pm 85 \mathrm{~min}$. All of the reported $\left[\mathrm{Fe}_{i}\right]$ reduction time constants for mc-Si wafers annealed at $400{ }^{\circ} \mathrm{C}$ with the presence of atomic hydrogen sources, either from $\mathrm{Al}_{2} \mathrm{O}_{3}$ films, ${ }^{10} \mathrm{SiN}_{\mathrm{x}}$ films, ${ }^{34}$ or hydrogen plasma, ${ }^{18}$ are comparable with our findings here (Fig. 3). This confirms the effect of hydrogen on the observed $\left[\mathrm{Fe}_{i}\right]$. Since the reduction time constants of $170 \mathrm{~min}$ and 200 min for the $\mathrm{SiN}_{\mathrm{x}}$ annealed samples are much smaller than the $1200 \mathrm{~min}$ measured on wafers with no hydrogen source, the trends presented in Fig. 3 are therefore dominated by the hydrogen effect.

\section{Effect of temperature}

Fig. 4 presents the average interstitial Fe concentrations of wafers before and after different annealing steps, for a range of temperatures from $400{ }^{\circ} \mathrm{C}$ to $900{ }^{\circ} \mathrm{C}$, and for two sets of samples - one with $\mathrm{SiO}_{2}$ and one with $\mathrm{SiN}_{\mathrm{x}}$ passivation layers, that is, without and with the hydrogen source during annealing. Different changes in the $\mathrm{Fe}_{i}$ concentrations can be observed between the two sets. For the $\mathrm{SiO}_{2}$ samples, after annealing at $400-700{ }^{\circ} \mathrm{C}$, some reductions in the $\mathrm{Fe}_{i}$ concentrations are observed, due to Fe precipitation; ${ }^{10}$ while at $800-900{ }^{\circ} \mathrm{C}$, the $\left[\mathrm{Fe}_{i}\right]$ of the $\mathrm{SiO}_{2}$ set remains almost unchanged within the error bars after anneals of $3 \mathrm{~min}$ and $30 \mathrm{~min}$, and an increase in $\left[\mathrm{Fe}_{i}\right]$ is seen after annealing at $900{ }^{\circ} \mathrm{C}$ for $5 \mathrm{~h}$, as a result of the dissolution of Fe precipitates. $^{40}$ This behaviour is consistent with the solubility-limit driven precipitation and dissolution of Fe which has been observed before and in our own recent study on the same material. ${ }^{10}$ That is, the changes in $\left[\mathrm{Fe}_{i}\right]$ of the $\mathrm{SiO}_{2}$ samples demonstrate the effect of temperature. On the other hand, the $\mathrm{SiN}_{\mathrm{x}}$ coated wafers, which were subjected to the same thermal anneals, consistently show much greater reductions in the $\mathrm{Fe}_{i}$ concentrations, for the entire temperature range of $400-900{ }^{\circ} \mathrm{C}$.

The Fe images of the $\mathrm{SiN}_{\mathrm{x}}$ coated wafers annealed at various temperatures all show that the reductions of $\left[\mathrm{Fe}_{i}\right]$ occur homogeneously across the wafer. An example can be seen in Figs. 5(k)-5(n) for a sample annealed at $700^{\circ} \mathrm{C}$. Note that the PL and Fe images of the $\mathrm{SiN}_{\mathrm{x}}$ sample after $30 \mathrm{~min}$ 

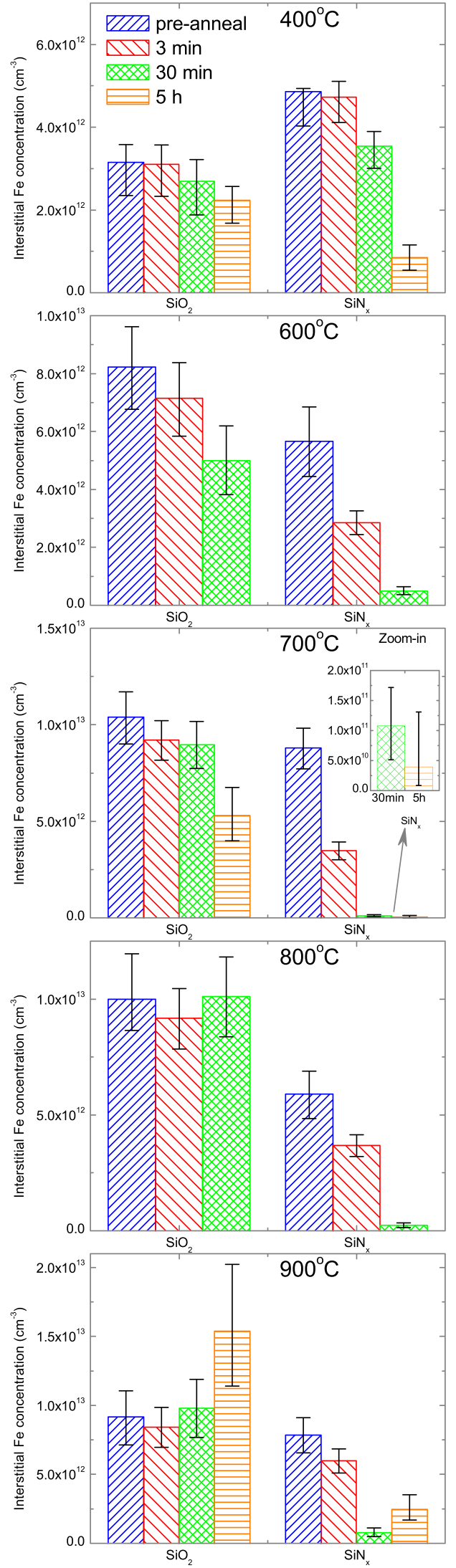

FIG. 4. Interstitial Fe concentrations across wafers with $\mathrm{SiO}_{2}$ passivation (no hydrogen source) and wafers with $\mathrm{SiN}_{\mathrm{x}}$ films (with hydrogen source) in the pre-annealed state, after annealing for short time $(3 \mathrm{~min}$ for those at $400-800^{\circ} \mathrm{C}$ and $140 \mathrm{~s}$ at $900^{\circ} \mathrm{C}$ ), after annealing for $30 \mathrm{~min}$, and after $5 \mathrm{~h}$ (only for the $400^{\circ} \mathrm{C}, 700^{\circ} \mathrm{C}$, and $900^{\circ} \mathrm{C}$ anneals). Note that the comparisons of the $\mathrm{SiO}_{2}$ and $\mathrm{SiN}_{\mathrm{x}}$ passivated wafers are made on sister wafers, except for the pair annealed at $400^{\circ} \mathrm{C}$. annealing are more smeared out than the rest, because of a large increase in the carrier diffusion length. The homogeneous $\left[\mathrm{Fe}_{i}\right]$ reduction is different from the effect of Fe precipitation, either during ingot cooling ${ }^{31}$ or during annealing, ${ }^{10}$ where the denuded zones of reduced $\left[\mathrm{Fe}_{i}\right]$ near grain boundaries can be clearly seen on the $\mathrm{Fe}$ images. ${ }^{10,31}$ The $\mathrm{SiO}_{2}$ sister wafers show the appearance of such denuded zones near some of the grain boundaries after annealing (although not so clear on logarithmically scaled Fe images). This is an additional proof that the greater reductions in $\left[\mathrm{Fe}_{i}\right]$ of the $\mathrm{SiN}_{\mathrm{x}}$ coated wafers are not caused by the accelerated gettering of Fe by the grain boundaries due to hydrogen-enhanced $\mathrm{Fe}$ diffusivity. Furthermore, at high temperatures of $800^{\circ} \mathrm{C}$ and $900{ }^{\circ} \mathrm{C}$, the respective $\mathrm{Fe}$ solubility limits ${ }^{4}$ are comparable or higher than the concentrations of $\mathrm{Fe}_{i}$ in the wafers, and thus $\mathrm{Fe}$ precipitation should not occur. Therefore, by comparing the changes in $\left[\mathrm{Fe}_{i}\right]$ of the $\mathrm{SiO}_{2}$ and $\mathrm{SiN}_{\mathrm{x}}$ sister wafers and examining the spatial changes in $\left[\mathrm{Fe}_{i}\right]$ across the mc-Si wafers, it is clear that the observed decreases in $\left[\mathrm{Fe}_{i}\right]$ of the $\mathrm{SiN}_{\mathrm{x}}$ set are not due to accelerated Fe precipitation, but some other impact of the presence of hydrogen.

Hydrogenation of shallow dopants in silicon, such as boron, is well known. ${ }^{11,12}$ However, the passivated boron should be reactivated by annealing at temperatures higher than $160^{\circ} \mathrm{C}^{11}$ which is lower than the PECVD process temperature. In addition, the boron concentration of the tested samples is $10^{16} \mathrm{~cm}^{-3}$, which is $3-4$ orders of magnitude higher than the dissolved $\mathrm{Fe}$ concentration, meaning that a moderate change in the $[\mathrm{B}]$ is unlikely to affect the measurement of $\left[\mathrm{Fe}_{i}\right]$. To confirm that the observed changes in interstitial $\mathrm{Fe}$ concentrations are not due to changes in the boron concentration, the resistivities of both $\mathrm{SiO}_{2}$ and $\mathrm{SiN}_{\mathrm{x}}$ samples in the ascut state, and before and after different annealing steps, were monitored by QSSPC dark conductance measurements. The resistivities were found to stay the same throughout the annealing steps and also between the $\mathrm{SiO}_{2}$ and $\mathrm{SiN}_{\mathrm{x}}$ sister wafers. The measured reductions in $\left[\mathrm{Fe}_{i}\right]$ of the $\mathrm{SiN}_{\mathrm{x}}$ coated samples are therefore not due to the hydrogenation of boron.

With increasing annealing time from $3 \mathrm{~min}$ to $30 \mathrm{~min}$, all of the samples annealed at $400-900^{\circ} \mathrm{C}$ show further reductions of the $\mathrm{Fe}_{i}$ concentrations, as can be seen in Figs. 4 and 6. After $30 \mathrm{~min}$, reductions of more than $90 \%$ of the original $\mathrm{Fe}_{i}$ concentrations have been achieved for samples annealed at $600-900{ }^{\circ} \mathrm{C}$, that is, those which require recoating of $\mathrm{SiN}_{\mathrm{x}}$ films in between the anneals. The impact of hydrogenation during the PECVD process, as disucssed above, is thus small compared to the effect of annealing. Some of the wafers, which were annealed at $400{ }^{\circ} \mathrm{C}, 700^{\circ} \mathrm{C}$, and $900^{\circ} \mathrm{C}$, were subjected to further anneals of $5 \mathrm{~h}$. As shown in Figs. 4 and 6 , the $5 \mathrm{~h}$ anneals result in further reductions in $\mathrm{Fe}_{i}$ concentrations for those at low temperatures of $400{ }^{\circ} \mathrm{C}$ and $700{ }^{\circ} \mathrm{C}$; whereas, for the $900^{\circ} \mathrm{C}$, this additional $5 \mathrm{~h}$ anneal leads to an increase in the $\left[\mathrm{Fe}_{i}\right]$ compared to the previous $30 \mathrm{~min}$ anneal. However, the $\mathrm{SiO}_{2}$ sister wafer also shows an increase in the $\mathrm{Fe}_{i}$ concentration after the same annealing step. Therefore, the observed increase in $\left[\mathrm{Fe}_{i}\right]$ of the $\mathrm{SiN}_{\mathrm{x}}$ sample could be related to the effect of precipitate dissolution which offsets the hydrogenation of dissolved Fe. Alternatively, this increase could also 


\section{Sample 1 - no hydrogen during annealing}

$\mathrm{PL}$ images

(a) Oxidised

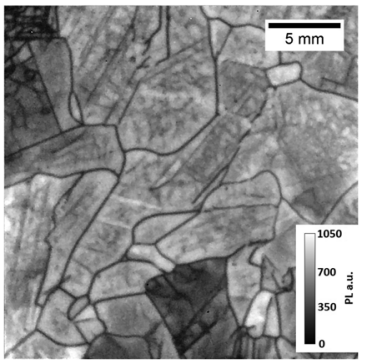

(d) Oxidised

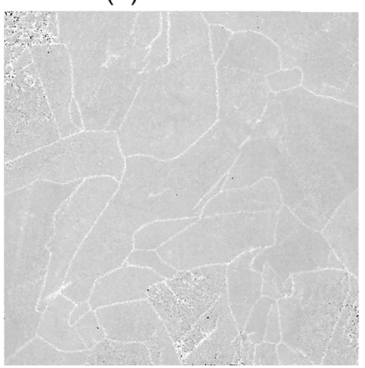

(b) $700^{\circ} \mathrm{C} 3$ min with $\mathrm{SiO}_{2}$

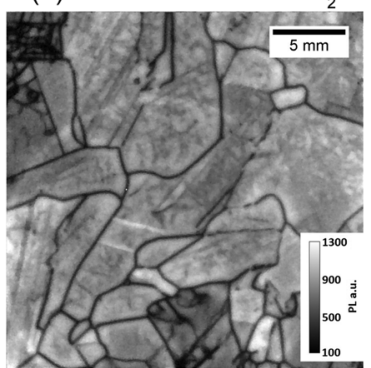

$\mathrm{Fe}_{\mathrm{i}}$ images

(e) $700^{\circ} \mathrm{C} 3 \mathrm{~min}$ with $\mathrm{SiO}_{2}$ (c) $700^{\circ} \mathrm{C} 30 \mathrm{~min}$ with $\mathrm{SiO}_{2}$

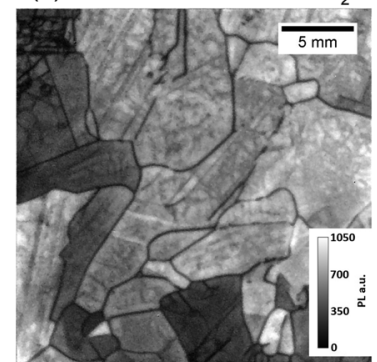

(f) $700^{\circ} \mathrm{C} 30 \mathrm{~min}$ with $\mathrm{SiO}_{2}$

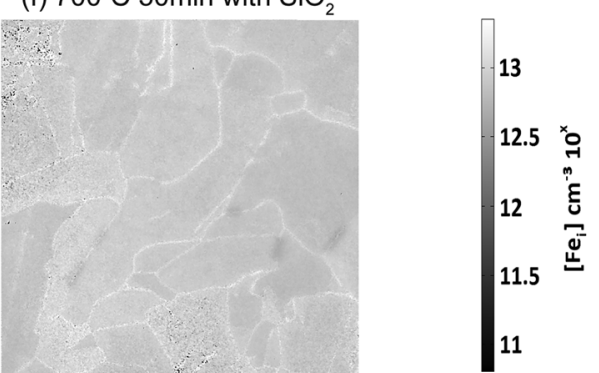

\section{Sample 2 - hydrogen present during annealing}

(g) Oxidised

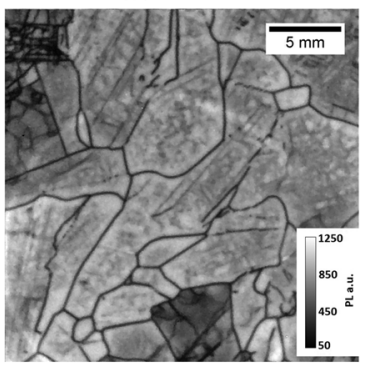

(k) Oxidised

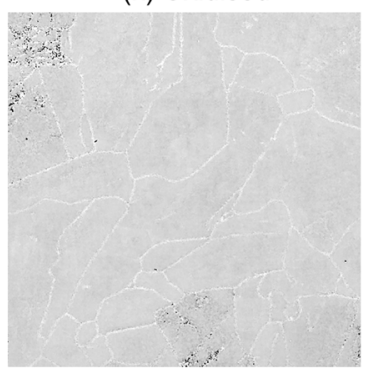

\section{$\mathrm{PL}$ images}

(h) HF dip, PECVD SiN

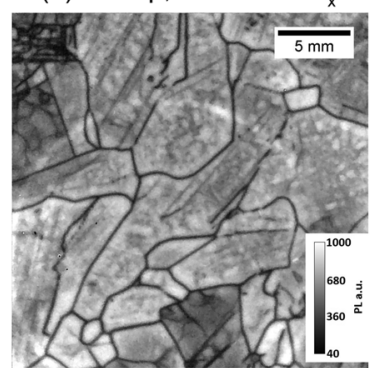

(i) $700^{\circ} \mathrm{C} 3 \min$ with $\mathrm{SiN}_{x}$

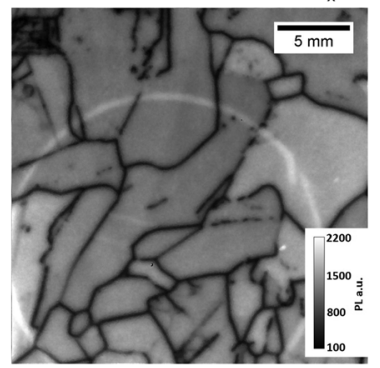

$\mathrm{Fe}_{i}$ images

\begin{abstract}
(I) HF dip, PECVD SiN
\end{abstract}

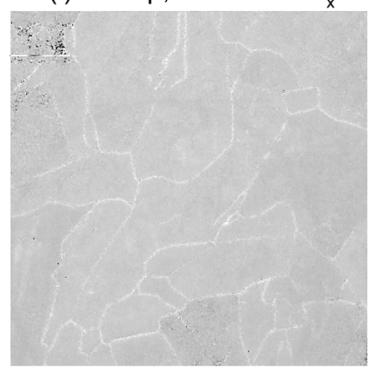

(m) $700^{\circ} \mathrm{C} 3 \mathrm{~min}$ with $\mathrm{SiN}_{\mathrm{x}}$

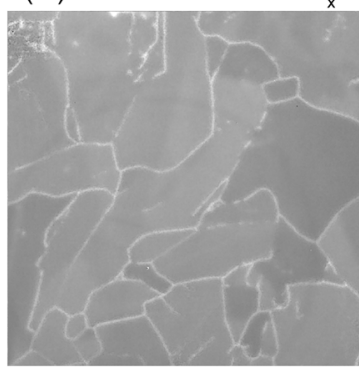

(j) $700^{\circ} \mathrm{C} 30$ min with $\mathrm{SiN}_{\mathrm{x}}$

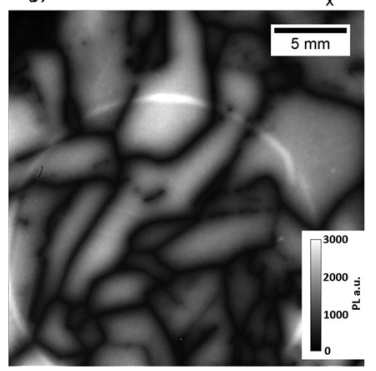

(n) $700^{\circ} \mathrm{C} 30 \mathrm{~min}$ with $\mathrm{SiN}_{x}$

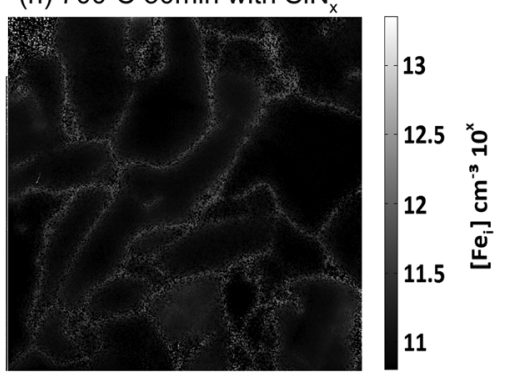

FIG. 5. Photoluminescence images [sub-figures (a)-(c) and (g)-(j)] and the corresponding interstitial Fe concentration images [(d)-(f) and (k)-(n)] of a pair of sister wafers which underwent the same anneals at $700^{\circ} \mathrm{C}$, with [(g)-(n)] and without [(a)-(f)] hydrogen source during annealing. Note that while the scales of the PL images (PL counts of arbitrary unit) vary to demonstrate the grain features, the Fe images have the same logarithmic scale to compare the concentrations and distributions of $\mathrm{Fe}_{i}$. The large "rings" appearing on the PL images are the QSSPC coil in the PL imager.

be caused by the increasing dominance of the dehydrogenation of $\mathrm{Fe}$ as time increases. It was found in Ref. 41 that increased annealing times actually cause degradation of carrier lifetime for edge-defined film-fed (EFG) and string ribbon silicon, and the effect was attributed to dehydrogenation.
It is known that during annealing the flux of hydrogen from the $\mathrm{SiN}_{\mathrm{x}}$ film into the silicon bulk slows down as time increases and the diffusivity of $\mathrm{H}$ is rather high. ${ }^{20}$ Hence, the reaction of $\mathrm{H}$ binding with defects and impurities in $\mathrm{mc}-\mathrm{Si}$ would dominate at the beginning of the anneals. However, as 


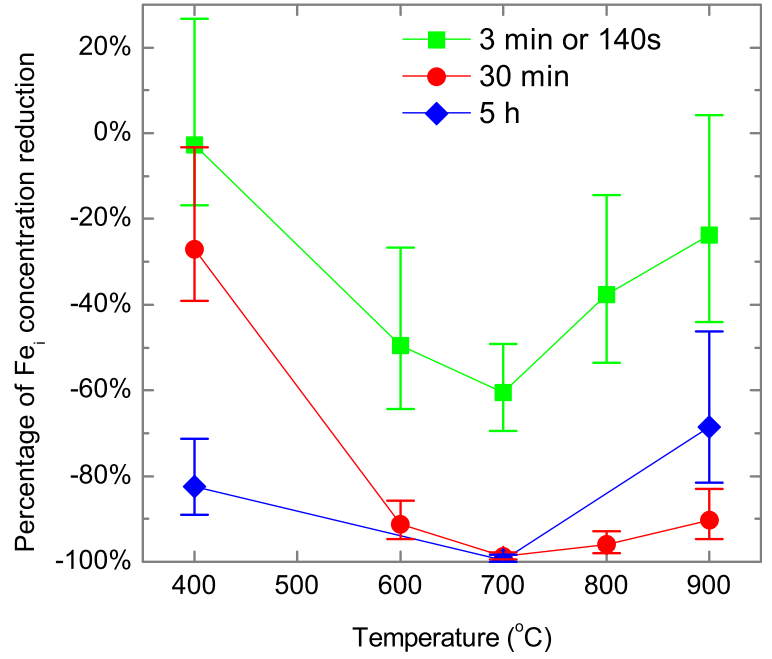

FIG. 6. Percentage of the $\left[\mathrm{Fe}_{i}\right]$ reduction after annealing with respect to the pre-annealed states, for wafers with $\mathrm{SiN}_{\mathrm{x}}$ coatings. The plot includes results of annealing at $400-900^{\circ} \mathrm{C}$ and for different cumulative times (although recoating was performed after each annealing step). Lines are guides to the eyes.

the annealing time increases, without constant replenishment of the $\mathrm{H}$ concentration from the films, the effusion of $\mathrm{H}$ out of the sample will start to dominate, the hydrogenation reaction will slow down, at some point allowing the reverse reaction of H-defect dissociation (i.e., dehydrogenation) to begin to dominate.

Fig. 6 plots the percentage reductions of the $\mathrm{Fe}_{i}$ concentrations after annealing with the $\mathrm{SiN}_{\mathrm{x}}$ samples, compared to the respective pre-annealed states, for different annealing temperatures and times. As shown in Fig. 6, for the same annealing times of $3 \mathrm{~min}, 30 \mathrm{~min}$, and $300 \mathrm{~min}$, the most effective reduction of the $\mathrm{Fe}$ point defect occurs at $700^{\circ} \mathrm{C}$. Note that the $900{ }^{\circ} \mathrm{C}$ short anneal was $140 \mathrm{~s}$ instead of $3 \mathrm{~min}$, because of equipment limitations. Hydrogen diffuses rapidly in silicon, ${ }^{12,20}$ and therefore the hydrogenation process is generally not diffusion-limited, ${ }^{17}$ especially at such high temperatures. For all of the tested annealing time durations, the $\left[\mathrm{Fe}_{i}\right]$ reduction effectiveness increases with temperature from 400 to $700{ }^{\circ} \mathrm{C}$. This agrees with the simulations shown in Fig. 2, which indicate that the $\mathrm{Fe}^{+}$and $\mathrm{H}^{-}$pairing rate should increase with temperature above $400^{\circ} \mathrm{C}$. Then from 700 to $900{ }^{\circ} \mathrm{C}$, the reduction of $\left[\mathrm{Fe}_{i}\right]$ becomes less effective. This may be attributed to either the dissolution of Fe precipitates or the reverse reaction of $\mathrm{Fe}-\mathrm{H}$ dissociation, that is, dehydrogenation, or a combination of both. Note that the effect of Fe precipitate dissolution is negligible for short annealing times of $3 \mathrm{~min}$ and $30 \mathrm{~min}$, as reflected by the small changes in the $\left[\mathrm{Fe}_{i}\right]$ of the $\mathrm{SiO}_{2}$ sister wafers shown in Fig. 4. Dehydrogenation is therefore the more likely explanation, as the measured $\mathrm{Fe}_{i}$ concentrations are the net effects of hydrogenation and dehydrogenation of $\mathrm{Fe}_{i}$. The effectiveness of hydrogenating defects in EFG and string ribbon silicon was also found to decrease at temperatures higher than $750{ }^{\circ} \mathrm{C}$, as a result of dehydrogenation. ${ }^{41}$

\section{B. Hydrogen passivation of other defects}

A high density of intra-grain defects were activated after the initial oxidation step at $1000^{\circ} \mathrm{C}$. This is clear when

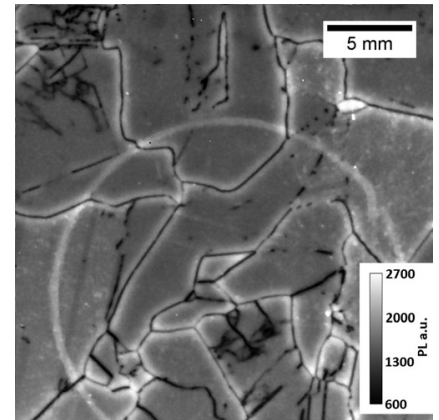

FIG. 7. PL image of a neighbouring wafer to the two samples shown in Fig. 5. The wafer was chemically polished and passivated using PECVD $\mathrm{SiN}_{\mathrm{x}}$, to show the grain structures of $\mathrm{mc}-\mathrm{Si}$ in the as-cut state. Note that the "ring" is the QSSPC coil.

comparing the PL images of the oxidised samples in Figs. $5(\mathrm{a})$ and $5(\mathrm{~g})$ with a neighbouring wafer in the as-cut state in Fig. 7. The as-cut neighbouring wafer was simply chemically polished and then passivated with PECVD silicon nitride, without any further steps, to allow examination of the bulk features in the as-cut state. As shown in Figs. 5(g) and 5(h), these activated defects remain unchanged after the PECVD $\mathrm{SiN}_{\mathrm{x}}$ deposition but were fully deactivated after a short hydrogenation step of 3 min (Fig. 5(i)), and they remain passivated during the subsequent long time anneals. On the other hand, wafers without the high temperature step show no such drastic change in the recombination activity of structural defects after hydrogenation. An example is shown in Fig. 8, which shows the PL images of a sample before and after hydrogenation, and the sample did not undergo any high temperature process prior to hydrogenation. As can be seen by comparing Fig. 8 with Figs. 5(h)-5(i), the intra-grain defects already present in the as-cut state are less readily hydrogenated than the defects activated after a high temperature process. This agrees with the observations reported in Ref. 42.

The structural defects in mc-Si, for example, dislocations and grain boundaries, become recombination active after being decorated by impurities. ${ }^{43}$ By comparing the PL images with the corresponding Fe images in Fig. 5, it can be seen that these high temperature activated defects are not related to interstitial Fe. Buonassisi et al. ${ }^{40}$ reported that after rapid thermal annealing at $860^{\circ} \mathrm{C}$ and $1000^{\circ} \mathrm{C}$, copper and nickel silicide precipitates are almost entirely dissolved.

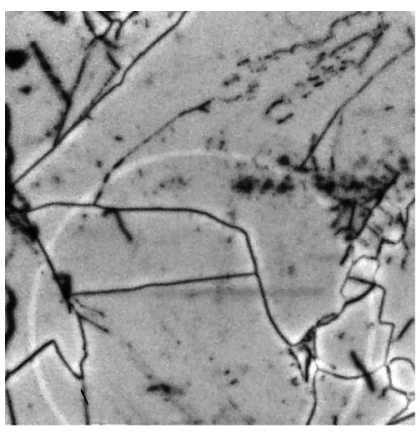

(a) Before hydrogenation

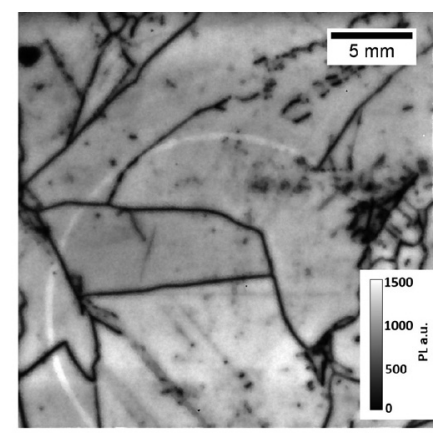

(b) After hydrogenation at $400^{\circ} \mathrm{C}$ for $5 \mathrm{~h}$
FIG. 8. PL images of the same wafer (a) in the as-cut state, that is, the wafer was only chemically polished and passivated using PECVD $\mathrm{SiN}_{\mathrm{x}}$ and (b) after hydrogenation at $400^{\circ} \mathrm{C}$ for $5 \mathrm{~h}$. 
Recombination activity of the intra-grain regions was also found to increase, ${ }^{40}$ and the spatial distributions look similar to the PL images from this study. Therefore, the activated defects may be due to the decoration of intra-grain dislocations by dissolved impurities, such as copper and nickel, and are then effectively hydrogenated during the subsequent anneals.

From the measured effective minority carrier lifetime $\left(\tau_{\text {eff }}\right)$ and the concentration of interstitial $\mathrm{Fe}\left(\left[\mathrm{Fe}_{i}\right]\right)$, the carrier lifetime due to recombination channels other than $\mathrm{Fe}_{i}$, $\tau_{\text {other }}$, can be estimated. The changes in $\tau_{\text {eff }}, \tau_{\text {other }}$, and $\left[\mathrm{Fe}_{i}\right]$ before and after annealing for different times are shown in Fig. 9, for the samples annealed at $400^{\circ} \mathrm{C}, 700^{\circ} \mathrm{C}$, and $900{ }^{\circ} \mathrm{C}$. The changes in $\tau_{\text {eff }}$ and $\tau_{\text {other }}$ are small for the $\mathrm{SiO}_{2}$ sample set, indicating that the observed large changes in lifetimes for the $\mathrm{SiN}_{\mathrm{x}}$ set are due to hydrogen. As shown in Fig. 9, with increasing annealing time, the $\mathrm{Fe}_{i}$ concentrations decrease and the effective carrier lifetimes increase. The only exception is after the $900{ }^{\circ} \mathrm{C} 5 \mathrm{~h}$ anneal, which resulted in a decrease in effective lifetime and an increase in $\left[\mathrm{Fe}_{i}\right]$, possibly because of the dissolution of impurities including Fe precipitates, or dehydrogenation, as discussed above.

On the other hand, $\tau_{\text {other }}$ first increases and then decreases to lower than the pre-annealed $\tau_{\text {other }}$ values with annealing time. The trend of $\tau_{\text {other }}$ with time could be related to the shifting dominance from hydrogenation to dehydrogenation as annealing proceeds, as a result of the effusion of hydrogen from the sample. This has less of an impact on interstitial $\mathrm{Fe}$, as shown by the different time at which maximum $\tau_{\text {other }}$ and minimum $\left[\mathrm{Fe}_{i}\right]$ occur (Fig. 9). The concentration of $\mathrm{H}$ from PECVD $\mathrm{SiN}_{\mathrm{x}}$ films is orders of magnitude higher than the concentration of interstitial $\mathrm{Fe}$ in mc-Si, ${ }^{20}$ and therefore $\mathrm{Fe}_{i}$ is less susceptible to the loss of hydrogen. The different response of interstitial $\mathrm{Fe}$ and other defects to the hydrogenation time could also be due to the different hydrogenation activation and deactivation energies for different species, leading to different sensitivity to the concentration changes in the reacting species. The optimum hydrogenation time for other defects is $45 \mathrm{~min}$ at $400^{\circ} \mathrm{C}$ and is $3 \mathrm{~min}$ at $600-900^{\circ} \mathrm{C}$. However, note that at $600-900^{\circ} \mathrm{C}$, very coarse time intervals were examined. The longer optimum hydrogenation time at a lower temperature can be explained by the balance of hydrogenation and dehydrogenation at different given thermal energies, that is, at different temperatures. As annealing time increases to long hours, the effect of impurity dissolution may also degrade the lifetime $\tau_{\text {other }}$, as in the case of the $900^{\circ} \mathrm{C}$ anneals.

\section{DISCUSSION}

It was conjectured in Refs. 18 and 19 that the reduced recombination activity of metals during $\mathrm{H}$ ion bombardment at $300{ }^{\circ} \mathrm{C}$ (Ref. 19) and the decreased $\mathrm{Fe}_{i}$ concentrations during $400^{\circ} \mathrm{C}$ hydrogen plasma exposure ${ }^{18}$ resulted from hydrogen-enhanced metal diffusivity that drives more precipitation/gettering of dissolved metals. In this paper, we show that the $\mathrm{Fe}_{i}$ concentrations also decrease substantially after annealing at temperatures higher than the Fe solubility limit. This has also been reported previously ${ }^{15-17}$ for other
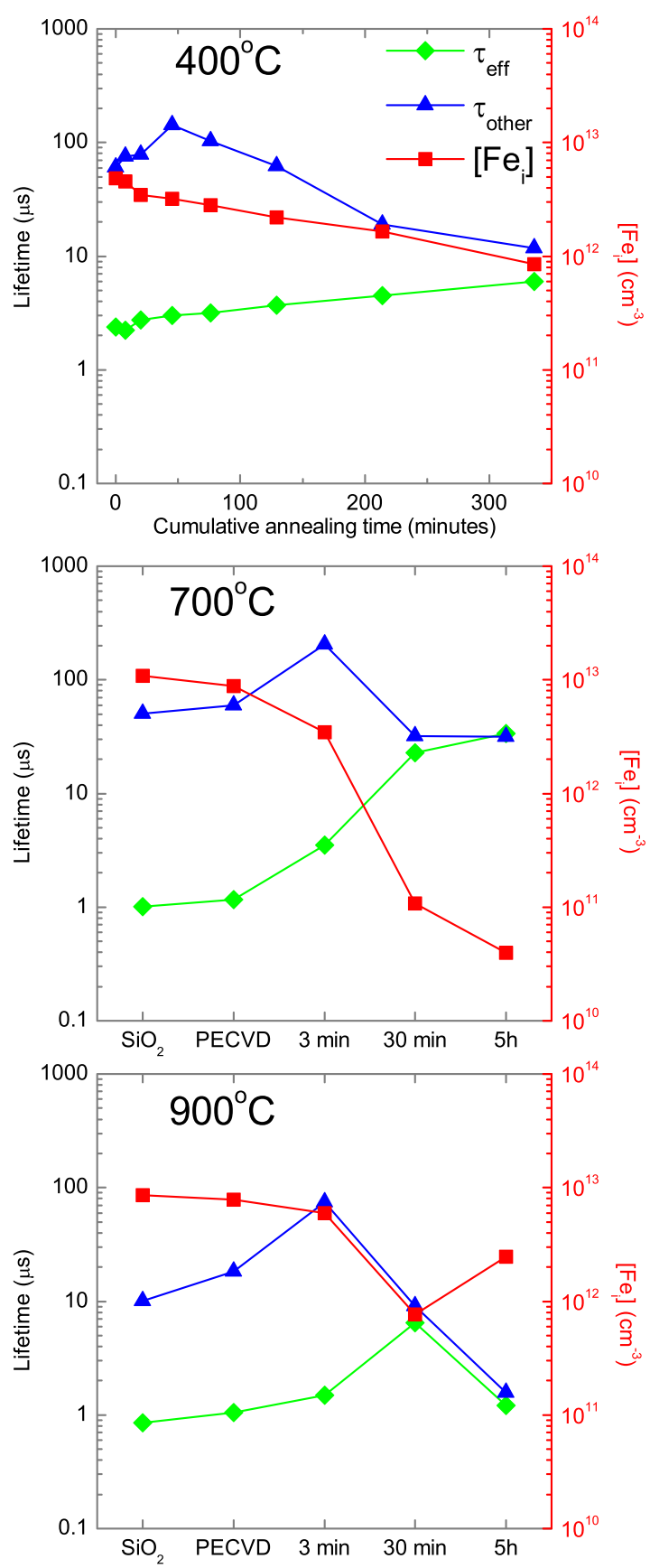

FIG. 9. Effective minority carrier lifetimes $\left(\tau_{\text {eff }}\right)$, lifetimes due to defects other than interstitial $\mathrm{Fe}\left(\tau_{\text {other }}\right)$, and concentrations of interstitial $\mathrm{Fe}\left(\left[\mathrm{Fe}_{i}\right]\right)$ of the same wafers before and after annealing for different times with $\mathrm{SiN}_{\mathrm{x}}$ films present at $400^{\circ} \mathrm{C}, 700^{\circ} \mathrm{C}$, and $900^{\circ} \mathrm{C}$. The lifetimes presented here are in the FeB paired state, at injection levels of $2 \times 10^{13}-4 \times 10^{13} \mathrm{~cm}^{-3}$. Lines are guides to the eyes.

high temperature anneals, in which case the precipitation of Fe cannot explain the decreased $\left[\mathrm{Fe}_{i}\right]$. In addition, the $\left[\mathrm{Fe}_{i}\right]$ images after annealing do not show the appearance or widening of the denuded zones near structural defects. Such denuded zones are characteristic of the inhomogeneous $\mathrm{Fe}$ precipitation process. ${ }^{10}$

We also considered the possibility that the substantial decline in $\left[\mathrm{Fe}_{i}\right]$ after annealing could be due to some uniform gettering sites by means of segregation at high temperatures, enhanced by the presence of hydrogen. For example, wafer 
surfaces or uniformly distributed dense dislocations which cannot be spatially resolved by PL imaging. However, this was found to be unlikely. McLean et al. ${ }^{17}$ reported that wafers which demonstrated an $80 \%$ decline in $\mathrm{Fe}_{i}$ concentrations after annealing with $\mathrm{SiN}_{\mathrm{x}}$ films at $700-900^{\circ} \mathrm{C}$, temperatures at which the precipitation of $\mathrm{Fe}$ was not found in the preliminary test, recovered to the initial $\mathrm{Fe}_{i}$ concentrations and carrier lifetimes after annealing at $900{ }^{\circ} \mathrm{C}$ for $1 \mathrm{~h}$ in nitrogen with the $\mathrm{SiN}_{\mathrm{x}}$ films removed, i.e., without the hydrogen source. McLean et al. ${ }^{17}$ used FZ wafers with known concentrations of implanted $\mathrm{Fe}$, and hence the impact of Fe precipitate dissolution on the $\left[\mathrm{Fe}_{i}\right]$ is not present. If the aforementioned hypothesis were true, that is, the observed $\left[\mathrm{Fe}_{i}\right]$ reductions were caused by the dissolved $\mathrm{Fe}_{i}$ atoms segregating to some uniform gettering sites within the mc-Si samples, the follow-up anneal at $900{ }^{\circ} \mathrm{C}$ for $1 \mathrm{~h}$ would result in further gettering of $\mathrm{Fe}_{i}$, at a slower rate if assuming the process is enhanced by hydrogen, and the already gettered Fe should not be ejected back into the bulk resulting in a return of the $\left[\mathrm{Fe}_{i}\right]$ to the pre-hydrogenated values. Therefore, the reductions in $\left[\mathrm{Fe}_{i}\right]$ after high temperature anneals are not likely due to the gettering of Fe via segregation at high temperatures. Furthermore, these results show that in the absence of a hydrogen source, the process of dehydrogenation becomes dominant. This is a similar phenomenon to that observed by Rohatgi et al. ${ }^{41}$ for the dehydrogenation of the previously hydrogenated EFG and string ribbon silicon, which demonstrates a significant drop in lifetime after firing the samples without the $\mathrm{SiN}_{\mathrm{x}}$ films.

The significant reduction of $\mathrm{Fe}_{i}$ concentrations after annealing for a range of temperatures is therefore more likely related to the interaction of interstitial $\mathrm{Fe}$ and atomic hydrogen, the effect of which passivates the electrical activity of interstitial $\mathrm{Fe}$ in silicon. We propose that it may be the reaction of $\mathrm{Fe}$ and $\mathrm{H}$ atoms, resulting in less recombination active $\mathrm{Fe}-\mathrm{H}$ complexes. The reaction is conjectured to be between positively charged $\mathrm{Fe}\left(\mathrm{Fe}^{+}\right)$and negatively charged $\mathrm{H}\left(\mathrm{H}^{-}\right)$. However, other possibilities are not excluded. Although the fraction of negatively charged $\mathrm{H}_{(}\left(\mathrm{H}^{-}\right)$is small, the total $\mathrm{H}$ concentration from PECVD $\mathrm{SiN}_{\mathrm{x}}$ is in the range of $10^{15}-10^{16} \mathrm{~cm}^{-3}, 20$ and thus a small fraction of $\mathrm{H}^{-}$is sufficient for the typical concentrations of dissolved $\mathrm{Fe}$ in $\mathrm{mc}-\mathrm{Si}$. The pairing of $\mathrm{Fe}^{+}$and $\mathrm{H}^{-}$and the dissociation of $\mathrm{Fe}-\mathrm{H}$, that is, the process of hydrogenation and dehydrogenation, can explain the observed effectiveness of the $\left[\mathrm{Fe}_{i}\right]$ reductions at various temperatures and times.

The activation energy for the hydrogenation of interstitial $\mathrm{Fe}$ was found to be in the range of $1.2 \mathrm{eV}-2 \mathrm{eV}$ in Ref. 17, and the binding energy of $\mathrm{Fe}$ and $\mathrm{H}$ was reported to be $1.5 \mathrm{eV}$ in Ref. 11. The significant reductions of $\left[\mathrm{Fe}_{i}\right]$ after annealing at $600-900^{\circ} \mathrm{C}$ suggest that the forward reaction of hydrogenation is favoured over the reverse reaction of dehydrogenation.

\section{CONCLUSION}

In this study, we present experimental evidence for the hydrogenation of interstitial iron in multicrystalline silicon, upon annealing of PECVD $\mathrm{SiN}_{\mathrm{x}}$ coated wafers for a range of temperatures from $400{ }^{\circ} \mathrm{C}$ to $900^{\circ} \mathrm{C}$ and for times from minutes to hours. Decreases of more than $90 \%$ of the initial dissolved iron concentrations are observed after a 30-min anneal at $600-900{ }^{\circ} \mathrm{C}$. At low temperatures where Fe precipitation also occurs, hydrogenation happens on a much faster time scale, acting as the dominant process. The most effective hydrogenation of dissolved $\mathrm{Fe}$ occurs at $700{ }^{\circ} \mathrm{C}$, where $99 \%$ of the initial $\left[\mathrm{Fe}_{i}\right]$ is hydrogenated after $30 \mathrm{~min}$, and a longer annealing time drives even further reductions in $\left[\mathrm{Fe}_{i}\right]$. This results in a large increase in the effective minority carrier lifetime for the $\mathrm{Fe}_{i}$-limited $\mathrm{mc}$-Si samples. Hydrogenation of other defects in the mc-Si, however, is more effective after shorter anneals. Further increases of the annealing time actually result in degrading $\tau_{\text {other }}$, as dehydrogenation becomes dominant. Hydrogenation of $\mathrm{Fe}$ also occurs during the PECVD $\mathrm{SiN}_{\mathrm{x}}$ deposition process, although the extent is less in comparison to annealing at higher temperatures. The results presented in this paper and those from high temperature hydrogenation studies ${ }^{15-17}$ show that the reduced interstitial Fe concentrations after hydrogen incorporation are unlikely to be caused by an accelerated internal gettering of $\mathrm{Fe}$ at structural defects due to enhanced diffusivity of $\mathrm{Fe}$ in the presence of hydrogen. The hydrogenation process may be related to the pairing of positively charged $\mathrm{Fe}\left(\mathrm{Fe}^{+}\right)$with negatively charged $\mathrm{H}\left(\mathrm{H}^{-}\right)$, forming less recombination active $\mathrm{Fe}-\mathrm{H}$ complexes. For temperatures above $400{ }^{\circ} \mathrm{C}$, simulations show that moderate excess carrier injection via illumination has little impact on the charge states of $\mathrm{Fe}$ and $\mathrm{H}$, and this is experimentally confirmed by the similar observed hydrogenation processes of wafers annealed with and without illumination at $400{ }^{\circ} \mathrm{C}$.

\section{ACKNOWLEDGMENTS}

This work was supported by the Australian Research Council and the Australian Renewable Energy Agency.

${ }^{1}$ A. A. Istratov, H. Hieslmair, and E. R. Weber, Appl. Phys. A 70, 489-534 (2000).

${ }^{2}$ D. Macdonald, A. Cuevas, A. Kinomura, Y. Nakano, and L. J. Geerligs, J. Appl. Phys. 97, 033523 (2005).

${ }^{3}$ T. Buonassisi, A. A. Istratov, M. D. Pickett, M. Heuer, J. P. Kalejs, G. Hahn, M. A. Marcus, B. Lai, Z. Cai, S. M. Heald, T. F. Ciszek, R. F. Clark, D. W. Cunningham, A. M. Gabor, R. Jonczyk, S. Narayanan, E. Sauar, and E. R. Weber, Prog. Photovoltaics: Res. Appl. 14, 513-531 (2006).

${ }^{4}$ A. A. Istratov, H. Hieslmair, and E. R. Weber, Appl. Phys. A 69, 13-44 (1999).

${ }^{5}$ S. P. Phang and D. Macdonald, J. Appl. Phys. 109, 073521 (2011).

${ }^{6} \mathrm{P}$. Manshanden and L. J. Geerligs, Sol. Energy Mater. Sol. Cells 90, 998-1012 (2006).

${ }^{7}$ M. Rinio, A. Yodyunyong, S. Keipert-Colberg, Y. P. B. Mouafi, D. Borchert, and A. Montesdeoca-Santana, Prog. Photovoltaics: Res. Appl. 19, 165-169 (2011).

${ }^{8}$ M. D. Pickett and T. Buonassisi, Appl. Phys. Lett. 92, 122103 (2008).

${ }^{9}$ S. M. Myers, M. Seibt, and W. Schröter, J. Appl. Phys. 88, 3795-3819 (2000).

${ }^{10}$ A. Y. Liu and D. Macdonald, J. Appl. Phys. 115, 114901 (2014).

${ }^{11}$ S. J. Pearton, J. W. Corbett, and T. S. Shi, Appl. Phys. A 43, 153-195 (1987).

${ }^{12}$ C. Dubé and J. I. Hanoka, in 31st IEEE Photovoltaic Specialists Conference, Lake Buena Vista, 2005 (IEEE, New York, 2005), pp. 883-888.

${ }^{13}$ M. Kouketsu and S. Isomae, J. Appl. Phys. 80, 1485-1487 (1996).

${ }^{14}$ A. J. Tavendale and S. J. Pearton, J. Phys. C: Solid State Physi. 16, 1665 (1983). 
${ }^{15}$ L. J. Geerligs, A. Azzizi, D. H. Macdonald, and P. Manshanden, in 13th Workshop on Crystalline Silicon Solar Cell Materials and Processes, Vail, Colorado, 2003 (National Renewable Energy Laboratory, Golden, Colorado, 2004), pp. 199-202.

${ }^{16}$ A. Azzizi, L. J. Geerligs, and D. Macdonald, in 19th European Photovoltaic Solar Energy Conference and Exhibition, Paris, 2004 (WIP Renewable Energies, Munich, 2004), pp. 1021-1024.

${ }^{17} \mathrm{~K}$. McLean, C. Morrow, and D. Macdonald, in 4th World Conference on Photovoltaic Energy Conversion, Waikoloa, 2006 (IEEE, New York, 2006), Vol. 1, pp. 1122-1125.

${ }^{18}$ P. Karzel, A. Frey, S. Fritz, and G. Hahn, J. Appl. Phys. 113, 114903 (2013).

${ }^{19}$ R. Singh, S. J. Fonash, and A. Rohatgi, Appl. Phys. Lett. 49, 800-802 (1986).

${ }^{20}$ M. Sheoran, D. S. Kim, A. Rohatgi, H. F. W. Dekkers, G. Beaucarne, M. Young, and S. Asher, Appl. Phys. Lett. 92, 172107 (2008).

${ }^{21}$ B. J. Hallam, P. G. Hamer, S. R. Wenham, M. D. Abbott, A. Sugianto, A. M. Wenham, C. E. Chan, X. GuangQi, J. Kraiem, J. Degoulange, and R. Einhaus, IEEE J. Photovoltaics 4, 88-95 (2014).

${ }^{22}$ T. Trupke, R. A. Bardos, M. C. Schubert, and W. Warta, Appl. Phys. Lett. 89, 044107 (2006).

${ }^{23}$ H. C. Sio, S. P. Phang, T. Trupke, and D. Macdonald, Sol. Energy Mater. Sol. Cells 131, 77-84 (2014).

${ }^{24}$ D. Macdonald, J. Tan, and T. Trupke, J. Appl. Phys. 103, 073710 (2008).

${ }^{25}$ N. M. Johnson, D. K. Biegelsen, M. D. Moyer, V. R. Deline, and C. A. Evans, Appl. Phys. Lett. 38, 995-997 (1981).

${ }^{26}$ G. Dingemans, W. Beyer, M. C. M. van de Sanden, and W. M. M. Kessels, Appl. Phys. Lett. 97, 152106 (2010).

${ }^{27}$ M. Wilde, M. Matsumoto, K. Fukutani, Z. Liu, K. Ando, Y. Kawashima, and S. Fujieda, J. Appl. Phys. 92, 4320-4329 (2002).
${ }^{28}$ R. A. Sinton and A. Cuevas, Appl. Phys. Lett. 69, 2510-2512 (1996).

${ }^{29}$ G. Zoth and W. Bergholz, J. Appl. Phys. 67, 6764-6771 (1990).

${ }^{30}$ D. H. Macdonald, L. J. Geerligs, and A. Azzizi, J. Appl. Phys. 95, 1021-1028 (2004).

${ }^{31}$ A. Y. Liu, D. Walter, S. P. Phang, and D. Macdonald, IEEE J. Photovoltaics 2, 479-484 (2012).

${ }^{32}$ D. Walter, A. Y. Liu, E. Franklin, D. Macdonald, B. Mitchell, and T. Trupke, in 38th IEEE Photovoltaic Specialists Conference (PVSC) (2012), pp. 000307-000312.

${ }^{33}$ B. Herzog, G. Hahn, M. Hofmann, I. Romijn, and A. Weeber, in 23rd European Photovoltaic Solar Energy Conference, Valencia, Spain, 2008 (WIP Renewable Energies, Munich, 2008), pp. 1863-1866.

${ }^{34}$ R. Krain, S. Herlufsen, and J. Schmidt, Appl. Phys. Lett. 93, 152108 (2008).

${ }^{35}$ W. Shockley and W. T. Read, Phys. Rev. 87, 835-842 (1952).

${ }^{36}$ R. N. Hall, Phys. Rev. 87, 387 (1952).

${ }^{37}$ C. Herring, N. M. Johnson, and C. G. Van de Walle, Phys. Rev. B 64, 125209 (2001).

${ }^{38}$ C. Sun, F. E. Rougieux, and D. Macdonald, "A unified approach to modelling the charge state of monatomic hydrogen and other defects in crystalline silicon," Phys. Rev. B (to be published).

${ }^{39}$ M. A. Green, J. Appl. Phys. 67, 2944-2954 (1990).

${ }^{40}$ T. Buonassisi, A. A. Istratov, S. Peters, C. Ballif, J. Isenberg, S. Riepe, W. Warta, R. Schindler, G. Willeke, Z. Cai, B. Lai, and E. R. Weber, Appl. Phys. Lett. 87, 121918 (2005).

${ }^{41}$ A. Rohatgi, D. S. Kim, K. Nakayashiki, V. Yelundur, and B. Rounsaville, Appl. Phys. Lett. 84, 145-147 (2004).

${ }^{42}$ L. J. Geerligs, Y. Komatsu, I. Rover, K. Wambach, I. Yamaga, and T. Saitoh, J. Appl. Phys. 102, 093702 (2007).

${ }^{43}$ J. Chen, T. Sekiguchi, D. Yang, F. Yin, K. Kido, and S. Tsurekawa, J. Appl. Phys. 96, 5490-5495 (2004). 